\title{
Environmental Quality and the Cost of Environmental Regulation: a Comparison of Scotland with the International Community
}

\author{
Jean Le Roux ${ }^{1 *}$, Evan Williams ${ }^{1,2}$, Andrew Staines' and Ariel Bergmann ${ }^{1,3}$ \\ ${ }^{1}$ Scottish Environment Protection Agency, Stirling, UK \\ ${ }^{2}$ University of Strathclyde, UK \\ ${ }^{3}$ Environmental Economics Research Group, University of Stirling, UK
}

\begin{abstract}
In today's global economy, assessing costs of compliance is crucial to understand how environmental regulations influence firms' behaviour and in particular their ability to compete at an international level. A three step methodology is used to conduct a comparison of Scotland's industry with the international community. The first step compares environmental protection expenditures among the European Community. The second step uses the Environmental Regulatory Regime Index developed by Porter and Esty to compare regulatory quality among 71 nations. The final step compares Scotland's environmental quality with the international community based on three criteria: $\mathrm{SO}_{2}, \mathrm{PM}_{10}$ and energy efficiency. Relative to the countries used in this research, Scotland is found to have a high quality regulatory regime, low costs of compliance for industry and a mixture of moderate to high environmental quality. Because significant deficiencies exist in the data, some uncertainties remain in the results. Published in 2007 with the permission of the Controller of Her Majesty's Stationery Office and the Queen's Printer for Scotland.
\end{abstract}

Received 3 April 2007; revised 19 June 2007; accepted 12 October 2007

Keywords: compliance costs; environmental regulation; better regulation; international benchmark

Introduction

COTLAND IS WELL KNOWN FOR THE QUALITY OF ITS ENVIRONMENT AND ITS LANDSCAPE, WHICH is widely perceived to be of good quality. However, there is a need to balance protection of the existing environmental quality while improving that quality where it is not satisfactory, against the costs of compliance that are placed on the business sector and the possible adverse effects on competitiveness. 
This paper compares the relative costs of environmental regulatory compliance paid by industrial sectors and the environmental quality that is being attained in different countries. A methodology is presented by which an international comparison of the costs of compliance with environmental regulations can be conducted.

There is limited published literature that compares the value of environmental regulation between countries. An important cornerstone of this literature, written by Esty and Porter (200I), of the Institute for Strategy and Competitiveness in the United States, provides the essential context of this paper.

The methodology presented follows three steps to qualify the value of a country's environmental regulation and to create a comparative ranking of the international community. The first step identifies the financial costs of compliance incurred by industry in member states of the European Union (EU). The second step estimates the quality of the regulatory regime that operates within each country. The third step is to quantify the actual and relative environmental performance of each country, with the end goal of developing an understanding of Scotland's effectiveness and efficiency in protecting the environment.

\section{EPE and the Cost of Compliance}

There have been few studies that compare the costs of compliance with environmental regulation using an international data set. Previously published studies have focused on a particular regime, environmental theme or individual nation (Atkins, 2005; DEFRA, 2006; Senat, I999; Bluffstone, I999; Khan et al., 2003). There are two major reasons for this limited quantity of international research: (I) the absence of a uniform and broadly used international standard to measure financial costs and (2) consistent and comparable environmental quality measures. Both information sets are necessary prerequisites for meaningful international comparison.

For this study the Environmental Protection Expenditure (EPE) data set, published by Eurostat, ${ }^{\mathrm{I}}$ is used. These data are consistent, comparable and available for all EU member states. The data set has also been extended to include Bulgaria and Romania (new members in 2007) and other potential entrants ${ }^{2}$ into the EU.

EPE is defined as 'monetary expenditures on all purposeful activities directly aimed at the prevention, reduction and elimination of pollution or any other degradation of the environment'3 (Eurostat, 2005). EPE data are available for only two major economic sectors, the public sector (Eurostat, 2006a) and industry

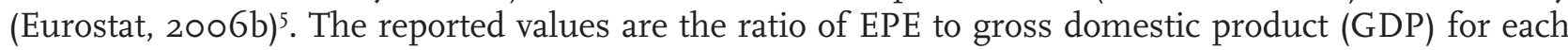
country. It is important to note that neither agricultural nor service sector expenditures are collected, and consequently they are not included in the EPE data. Published EPE values do not represent the total EPE for any given country, but are useful for comparing the costs borne by a country's business sectors.

Eurostat has given the following explanation for selective collection of EPE data: 'The opinion has been for years to focus EPE statistics on heavy industry where pollution is a problem and where actions are undertaken considerably. As the service sector's main environmental problems are energy efficiency and the organization of transportation modes, the interest has been low for collecting EPE statistics on them'. ${ }^{6}$

\footnotetext{
${ }^{\mathrm{I}}$ Eurostat Home Page www.ec.europa.eu/eurostat/

${ }^{2}$ Other potential entrants are Turkey, Switzerland, Iceland, Norway and Croatia.

${ }^{3}$ For a complete definition see p. 7 of Eurostat (2005). www.eustatistics.gov.uk/Download.asp?KS-NQ-05-009-EN_tcm90-25599.pdf

${ }^{4}$ Complete data set http://epp.eurostat.ec.europa.eu/portal/page?_pageid=I073,4687009I\&_dad=portal\&_schema=PORTAL\&p_product_code= DDCIIO24

${ }^{5}$ Complete data set http://epp.eurostat.ec.europa.eu/portal/page?_pageid=I073,4687009I\&_dad=portal\&_schema=PORTAL\&p_product_code= DDCiI536

${ }^{6}$ Personal communications between Le Roux and Eurostat, 2006.
} 
Several important assumptions are imposed as a result of this data limitation. The first assumption is that EPE values can act as a proxy for the full costs of compliance of each country's industrial sector. The second assumption is that the quality and accuracy of EPE and GDP statistics are consistent across all nations covered by the Eurostat report, thereby making international comparisons valid. It is understood that the reported EPE values do not capture or report the complete costs of compliance for any country. However, this paper assumes that EPE is positively correlated with actual, yet uncertain, costs of complying with environmental regulation. Compliance with environmental regulation is assumed to be the principal motivator of EPE.

Eurostat reports EPE values at the national level, and as the UK is the member state no separate expenditures are reported for Scotland. This necessitates the third assumption, that the UK's EPE value can be used as a proxy to represent a Scotland EPE value.

Several factors support this assumption. Scotland's economic make-up is similar to that of the UK, with only slight variations in the four basic sectors (industry, agriculture, service and public sector). The Scottish economy is a regional sub-unit of the UK economy and shares a common social, political and economic heritage; it is therefore considered to be a close representation of the UK. The differences in structure suggest that the total costs paid by the business sector in Scotland may actually be lower.

Based on EPE data ${ }^{5}$ for the period 2000-2002, the UK spends a smaller proportion of its GDP on environmental protection in industry than most other European countries (see Figure I). Of the EUI5, four member states have below average expenditures: the UK, France, Spain and Portugal. The latter three spend a smaller portion of their GDP on protection than the UK.

As seen in Figure I, the UK has below average expenditures, even when the larger EU25 group of nations is used for comparison. However, two new members, Latvia and Cyprus, are seen to spend a lower proportion of GDP than the UK.

The UK's EPE ranking on proportion of GDP spent on industry relative to other European countries contradicts claims by domestic industry and business interests that costs of compliance with environmental protection are high in the UK. In fact, the evidence shows that the portion of GDP spent is low.

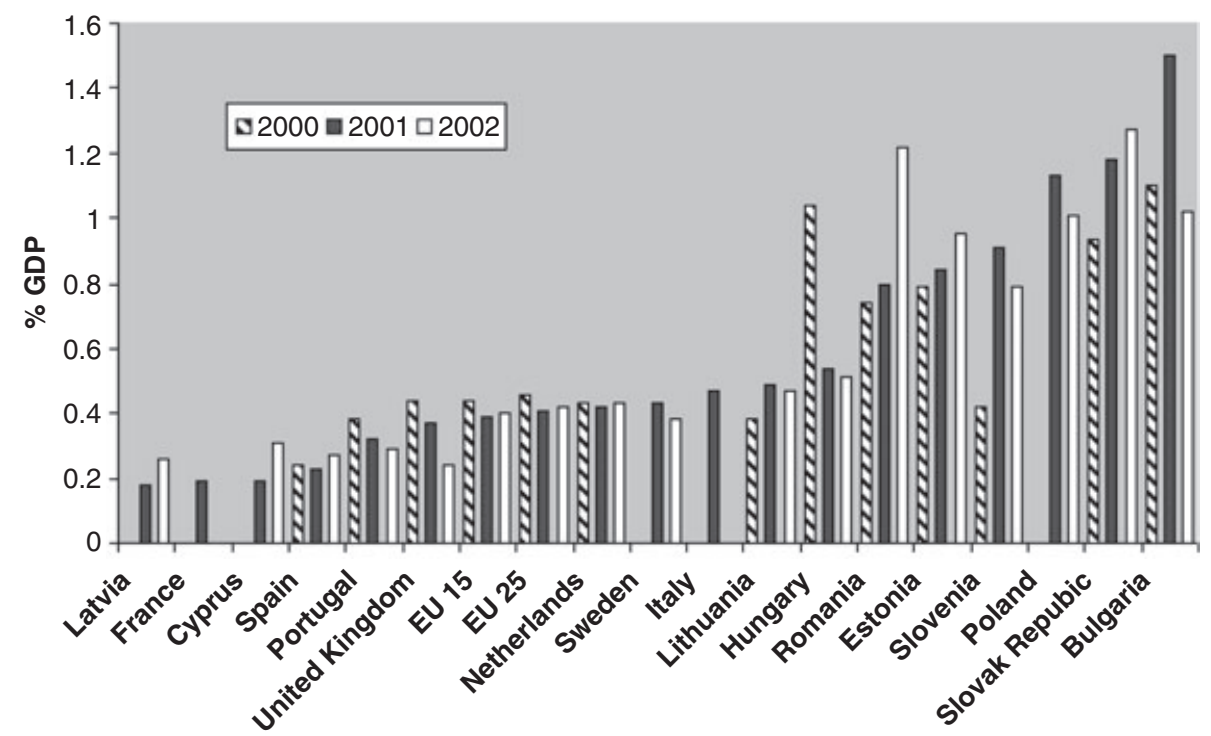

Figure 1. Environmental Protection Expenditure for Industry, 2000-2002 


\begin{tabular}{llccc}
\hline & & 2000 & 2001 & 2002 \\
\hline EU15 & UK rank & 3 & 4 & 5 \\
& Number of countries & 6 & 7 & 5 \\
Extended EU*** & 8 & 12 & 15 \\
& UK rank & 13 & 17 & 15 \\
\hline
\end{tabular}

Table 1. Comparative rank of EPE for industry, 2000-2002

*** Extended EU refers to the EU 25, plus future entrants (Romania and Bulgaria) and potential entrants (Turkey, Switzerland, Iceland, Norway and Croatia).

Table I summarizes the comparative EPE rank of the UK for the period 2000-2002, by EPE in industry sector. The rank order is based on decreasing percentage of GDP spent on EPE; i.e., in 2002 the UK was ranked lowest, fifth of five, for EPE in industry.

\section{ERRI and Measuring the Quality of Environmental Regulation}

Financial costs are not the only criterion that should be included in any examination of the cost of compliance with environmental regulation. The quality of the regulatory regime needs to be considered as well. The quality of regulation can be a significant driver for an unnecessarily high financial burden on both the public sector and the private sector.

In this section, the work of Esty and Porter (200I) is relied upon to identify the qualitative nature of the UK's and Scotland's regulatory regime and ranks it in relation to other countries. It should be emphasized that any assessment of regulatory regimes is by its nature a subjective undertaking and difficult to assess. However, the chosen methodology does provide valid comparisons.

Esty and Porter developed a multiple indicator index, the Environmental Regulatory Regime Index (ERRI), ${ }^{7}$ which quantifies the quality of regulation for a country.

Before looking into the details of Scotland's ranking, it is probably worth clarifying a few aspects regarding these criteria. Table 2 presents the details of the data used.

The first potential issue is the subjectivity of the criteria used. Given the wide range of existing regulations around the world, it is hard to use a complete quantitative and objective benchmark. Therefore, it is hard to avoid subjective aspects. However, most data have been assessed by surveys in which businesses as well as government leaders from around the world took part. Therefore, if we assume that the criteria considered give a pretty good overview of what should be taken into account when assessing environmental regulation, the method used is probably not far from a second best. However, two criteria in particular seem hard to assess accurately.

The sophistication of regulatory structures, even if only based on surveys, takes into account a wide range of parameters: options for achieving compliance in environmental regulations, confusing aspects of regulation, early or late regulation enactment compared to other countries. All these aspects give a pretty accurate idea of what we can expect from a sophisticated regime.

Regarding the quality of institutions, all components are actually quantitative: number of organizations that are members of IUCN, number of memberships in environmental intergovernmental organizations and number of companies utilizing an EMS (environmental management system).

The second potential issue is the data on regulatory enforcement. There is a risk of reaching wrong conclusions depending on how the difference between sanctions-based and compliance-based approaches

${ }^{7}$ Esty and Porter (200I). www.isc.hbs.edu/GCR_200I2002_Environment.pdf 


\begin{tabular}{|c|c|}
\hline Air regulation & Stringency of air regulation (high $=$ more stringent) \\
\hline Toxic waste regulation & Stringency of toxic waste regulations \\
\hline Chemical regulation & Stringency of manufacturing chemical use regulations \\
\hline Overall regulation & Stringency of overall environmental regulation \\
\hline \multicolumn{2}{|r|}{ Regulatory structure } \\
\hline Flexibility & Options for achieving compliance in environmental regulations \\
\hline Stability & Environmental regulations in your country are confusing and frequently changing \\
\hline Early or late & Environmental regulations are enacted ahead or much later than other countries \\
\hline $\begin{array}{l}\text { Compliance hurts or helps } \\
\text { competitiveness }\end{array}$ & Complying with environmental standards hurts/helps competitiveness \\
\hline
\end{tabular}

Information

ESI variables-\%

Sustainable development info

Number of sectoral EIA guidelines

Number of environmental strategies \& action plans
Percentage of ESI variables in publicly available data sets

Availability of sustainable development information at the national level

Number of sectoral EIA guidelines

Number of environmental strategies \& action plans

\section{Subsidies}

Government subsidies

Government subsidies in your country encourage inefficient use of energy or materials or there are no subsidies

\section{Regulatory enforcement}

Enforcement

Environmental regulations are not enforced erratically or are enforced consistently and fairly

International agreements

Compliance with international agreements is a high priority in your country's government

\section{Environmental institutions}

IUCN

Memberships

Prevalence of ISO 14000
Number of IUCN member organizations, 1998

Number of memberships in environmental intergovernmental organizations, 1998 How many companies utilize environmental management systems such as ISO 14000

Table 2. Categories of the Environmental Regulatory Regime Index

Esty and Porter (2001).

to regulation is considered. The risk is to assume that more enforcement means better environmental quality. Previous research (Vogel, I986) has indeed shown that, although these two approaches have different implications in terms of costs for the public and private sectors, they actually deliver roughly the same level of efficacy.

The enforcement variable is based on survey data that goes by the strength of regulations as perceived by the regulatory community. This strength would encompass both compliance based and sanctions 


\section{ERRI}

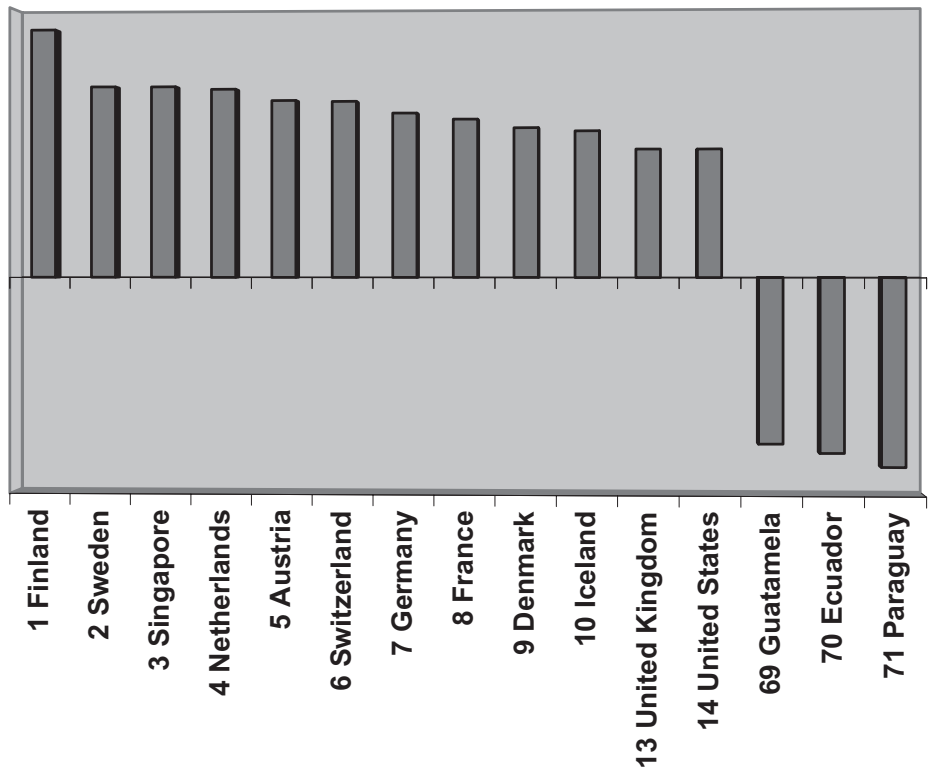

Figure 2. Environmental Regulatory Regime Index

based efforts. Nothing is therefore assumed about the outputs in the model: rather it examines various inputs to see whether they drive outputs.

\section{Scotland's Ranking}

The ERRI ranking includes the UK but as before does not separately identify Scotland. Because the ERRI index is a complex aggregation of data, it is beyond the scope of this paper to replicate the methodology in an attempt to create an ERRI profile for Scotland. This necessitates another assumption, that Scotland's profile within the ERRI framework is the same as the UK's, and therefore Scotland's rank can be assumed to be equivalent to that of the UK. This assumption is based on a substantial and significant level of identical or equivalent environmental regulation between England and Wales, and Scotland, where environmental issues are a devolved issue.

An expanded sample set is used to compare the UK, including Scotland, in terms of the relative quality of its regulatory framework. In addition to European countries the sample includes developing countries and large economies.

National ERRI scores are presented in Table 3 (Figure 2 illustrates these results graphically). The UK is ranked I3th among the global community (7I countries considered). With the exception of the Scandinavian countries and France and Germany, the UK performs better than most other countries in Europe.

Environmental quality is generally considered to be a normal good: when income increases, greater quality or quantity is demanded. As per capita income of a nation increases, both individuals and society as a whole are expected to have an increasing willingness to pay for improved environmental quality. Economic theory predicts that the wealth and income of a nation can be a significant factor when considering the environmental quality of a country. Specifically, there is believed to be a relationship between the wealth of a nation and its environmental policies (Grossman and Krueger, I995).

Using this premise, Esty and Porter examined the correlation between a country's GDP and the quality of its environmental regulation. Simple linear regression analysis (see box I) compares the actual ERRI 


\begin{tabular}{|c|c|c|c|c|c|}
\hline Rank & Country & Score & Rank & Country & Score \\
\hline 1 & Finland & 2.303 & 23 & Hungary & 0.283 \\
\hline 2 & Sweden & 1.772 & 24 & Slovenia & 0.209 \\
\hline 3 & Singapore & 1.771 & 25 & Chile & 0.177 \\
\hline 4 & Netherlands & 1.747 & 26 & Czech Republic & 0.073 \\
\hline 5 & Austria & 1.641 & $\ldots$ & $\ldots \ldots \ldots \ldots$ & $\ldots \ldots$ \\
\hline 6 & Switzerland & 1.631 & 29 & Poland & 0.005 \\
\hline 7 & Germany & 1.522 & $\ldots$ & $\ldots \ldots \ldots \ldots$ & $\ldots \ldots$ \\
\hline 8 & France & 1.464 & 31 & Portugal & -0.028 \\
\hline 9 & Denmark & 1.384 & $\ldots$ & $\ldots \ldots \ldots$ & $\ldots \ldots$ \\
\hline 10 & Iceland & 1.354 & 33 & Latvia & -0.036 \\
\hline 11 & New-Zealand & 1.299 & $\ldots \ldots$ & $\ldots \ldots \ldots$ & $\ldots \ldots \ldots$ \\
\hline 12 & Canada & 1.297 & 39 & Lithuania & -0.146 \\
\hline 13 & UK & 1.185 & $\ldots \ldots$ & $\ldots \ldots \ldots$ & $\ldots \ldots \ldots$ \\
\hline 14 & United States & 1.184 & 47 & Bulgaria & -0.584 \\
\hline 15 & Belgium & 1.159 & $\ldots$ & $\ldots \ldots \ldots$ & $\ldots \ldots \ldots$ \\
\hline 16 & Australia & 1.083 & 49 & Greece & -0.619 \\
\hline 17 & Japan & 1.057 & $\ldots \ldots$ & $\ldots \ldots \ldots$ & $\ldots \ldots \ldots$ \\
\hline 18 & Norway & 1.045 & 57 & Russia & -0.895 \\
\hline 19 & Ireland & 0.546 & $\ldots \ldots$ & $\ldots \ldots \ldots \ldots$ & $\ldots \ldots \ldots$ \\
\hline 20 & Italy & 0.498 & 64 & Romania & -1.268 \\
\hline 21 & Spain & 0.437 & 65 & Ukraine & -1.297 \\
\hline \multirow[t]{2}{*}{22} & Estonia & 0.296 & $\cdots \cdots$ & $\ldots \ldots \ldots$ & $\ldots \ldots \ldots$ \\
\hline & & & ו & Paraguay & -1.743 \\
\hline
\end{tabular}

Table 3. ERRI rank and score by country

\section{What is a linear regression?}

- The objective of linear regression analysis is to find a simple mathematical equation, a straight line, which predicts the value of one variable given another variable, i.e. given the GDP and the ERRI of numerous countries, determine the predicted index value for any single country.

- predicted ERRI $=a *$ GDP $+b$

- Subtracting the predicted ERRI of a country from its true ERRI index gives a residual. The residual indicates if a country is an over performer or an under performer relative to the experience of all other countries.

Box 1. Linear regression

score of a country to its predicted value based on the country's per capita GDP. This allows for a comparison of underperforming and overperforming on environmental quality compared to the expected performance based on the common international experience.

The UK is ranked seventh of I8 (Table 4), among the countries classified as 'high income', ${ }^{8}$ with both France and Germany outperforming the UK. Four countries, Switzerland, Denmark, Iceland and Canada, were ranked higher than the UK by the actual ERRI score, but ranked lower than the UK when per capita GDP was considered.

Figure 3 summarizes the UK's relative rank based on regression residuals. The results indicate that the UK's environmental regulatory regime is of high quality and stands up well to international comparison.

\footnotetext{
${ }^{8}$ Esty and Porter (200I) define 'high income' countries as having per capita income greater than US\$23 000.
} 
ERRI (linear regression residuals)

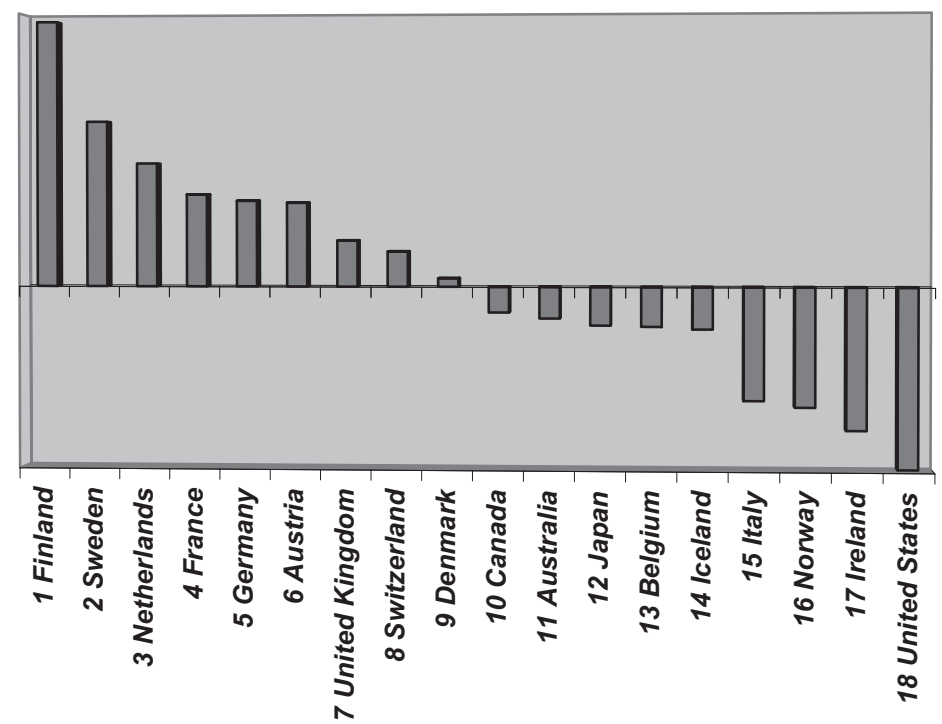

Figure 3. Regression residuals of Environmental Regulatory Regime Index on GDP

\begin{tabular}{|c|c|c|c|c|c|c|}
\hline & \multicolumn{4}{|c|}{ Absolute values } & \multirow{2}{*}{\multicolumn{2}{|c|}{$\begin{array}{c}\text { Linear regression } \\
\text { High income countries }\end{array}$}} \\
\hline & \multicolumn{2}{|c|}{ World } & \multicolumn{2}{|c|}{ EU } & & \\
\hline & UK Rank & No. of countries & UK Rank & No. of countries & UK Rank & No. of Countries \\
\hline ERRI & 13 & 7 & 7 & 21 & 7 & 18 \\
\hline
\end{tabular}

Table 4. Ranking of the UK on the quality of regulation

It can be stated that Scotland also demonstrates high quality environmental regulation based on the previously mentioned assumptions. As Scotland's per capita GDP is slightly lower than the UK's, the implication is that using this measure Scotland would rank higher than the UK as a whole.

\section{Measure of the Quality of the Environment}

There are no uniform reporting standards for environmental quality that can be used to compare EU member states. Even within the UK, depending on the specific environmental information being reported, different standards may be used between Scotland, Northern Ireland, Wales and England. Where consistent and comparable standards are used, the information is aggregated from the regions and reported as a UK total. The authors have been unable to find any source that provides disaggregated data.

However, the Scottish government is currently in the process of identifying data that may be used to compare the Scottish environment with EU countries. Publication of the information is scheduled for delivery in 2007.

To advance this investigation the authors have chosen to provide an ad hoc analysis of Scotland's environment in comparison to EU countries and the international community. Following the methodology established by Esty and Porter, three indicators of environmental quality are used to examine the performance of countries. Both the absolute quantity (Table 5) and the relative quantity (based on a country's per capita 


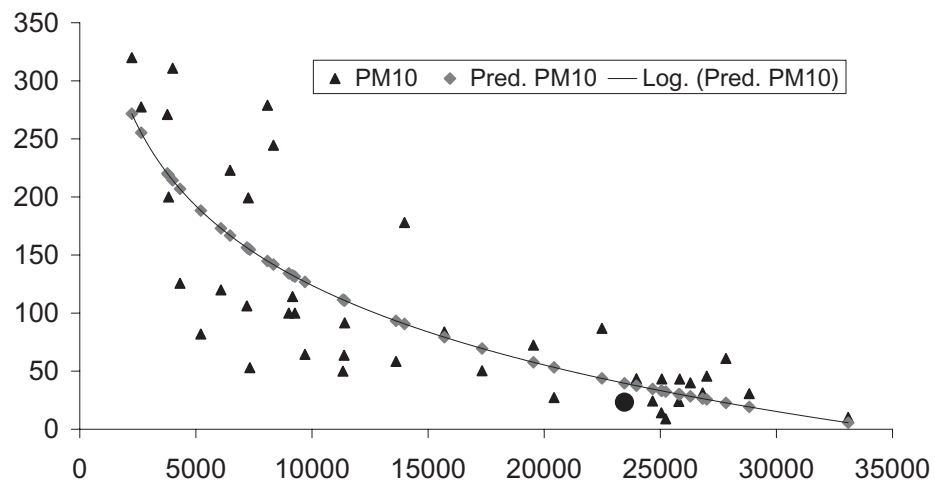

Figure 4. Urban PMro pollution, actual vs. predicted levels

\begin{tabular}{llllll}
\hline & \multicolumn{2}{c}{ World } & & \multicolumn{2}{c}{ EU25 } \\
\cline { 2 - 3 } \cline { 5 - 6 } & Scottish rank & No. of countries & & Scottish rank & No. of countries \\
\hline PM10 & 4 & 42 & 3 & 15 \\
SO2 & 28 & 47 & 15 & 19 \\
Energy efficiency & 38 & 71 & 17 & 22 \\
\hline
\end{tabular}

Table 5. Ranking of Scotland by absolute value of indicator

\begin{tabular}{llllll}
\hline & \multicolumn{2}{c}{ World } & & \multicolumn{2}{c}{ EU25 } \\
\cline { 2 - 3 } \cline { 5 - 6 } & Scottish rank & No. of countries & & Scottish rank & No. of countries \\
\hline PM10 & 19 & 43 & 9 & 17 \\
SO2 & 36 & 48 & 18 & 21 \\
Energy efficiency & 56 & 71 & 19 & 21 \\
\hline
\end{tabular}

Table 6. Rank based on residuals (relative performance based on per capita GDP)

GDP, Table 6) of an environmental indicator are used to rank the performance of countries. Significant changes in the ranking of some countries do occur, depending on which of the two methods of analysis is used. The three indicators used are (I) urban PMio levels, (2) SO2 levels and (3) energy efficiency.

In Figure 4 the actual versus predicted levels of urban PMio pollution for 7I countries are presented. If a country lies above the regression line, it is underperforming given its level of per capita GDP; if the country lies below the line it is on overperformer given the level of per capita GDP. Countries above the line have a negative residual, while those lying below the line show a positive residual.

In Figure 4, Scotland (which is represented by the black spot to the left of the 25 ooo value) lies below the high performers and to the right hand side, which indicates that it is an overperformer and would qualify as a high income country if it were sovereign.

Any environmental data that can be used for international comparisons have limitations that should be considered. Both the $\mathrm{PM}_{\text {Iо }}$ and the $\mathrm{SO}_{2}$ indicators are principally concerned with urban environments and populations. These indicators do not cover major environmental themes such as land use, water or biodiversity. Moreover, countries with cold climates tend to be less energy efficient due to greater heating requirements. Scandinavian countries, for example, do not rank high on this issue, whereas 
they are generally known to have a high quality environment. The Scottish climate is colder than most European countries, so the use of this variable penalizes its performance. In addition, $45 \%$ of Scotland's electricity comes from non-fossil fuel sources (KSES, 2006); this high proportion of clean or renewable energy is not taken into account when considering energy efficiency.

\section{Recommendation and Conclusions}

This paper proposes and attempts to develop a framework by which the costs of compliance with environmental regulations borne by industry can be analysed and compared on an international basis. This objective has been met; however, substantial uncertainty in the final answer exists. This process has highlighted shortcomings in available information. Two significant areas that need further exploration and development are improved financial accounting systems that are both efficient and effective at identifying compliance costs and a need for uniform, consistent and broadly accepted environmental quality measurements.

In conclusion, it can be stated that Scotland has a high quality regulatory process, imposes relatively low costs of compliance on its industry and has an environment that is a mixture of moderate to excellent quality. The costs of compliance with environmental regulation are shown to be of good value in Scotland.

\section{Acknowledgement}

The views expressed in this paper are those of the authors and do not reflect the policy or view of the Scottish Environment Protection Agency.

\section{References}

Bluffstone R. I999. Are the costs of pollution abatement lower in Central and Eastern Europe? Evidence from Lithuania. Environment and Development Economics 4(4): 449-470.

Department of Environment, Food and Rural Affairs (DEFRA), UK. 2006. Environmental Protection Expenditure by Industry: 2004 UK Survey. DEFRA. http://www.defra.gov.uk/environment/statistics/envsurvey/index.htm [24 January 2007].

Esty D, Porter M. 200I. Ranking National Environmental Regulation and Performance: a Leading Indicator of Future Competitiveness, The Global Competitiveness Report 200I-2002. New York: Oxford University Press. www.isc.hbs.edu/GCR_200I2002_ Environment.pdf [24 January 2007].

Eurostat. 2005. Environmental Protection Expenditures by Industry in the European Union, Statistics in Focus Environment and Energy, European Communities.

Eurostat. 2006a. Current Environmental Expenditure by Public Sector. http://epp.eurostat.ec.europa.eu/portal/page?_ pageid=I073,4687009I\&_dad=portal\&_schema=PORTAL\&p_product_code=DDCiIO24 [24 January 2007].

Eurostat. 2006b. Environmental Protection Expenditure by Industry. http://epp.eurostat.ec.europa.eu/portal/page?_ pageid=I073,4687009I\&_dad=portal\&_schema=PORTAL\&p_product_code=DDCII536 [24 January 2007].

Grossman G, Krueger A. I995. Economic growth and the environment. Quarterly Journal of Economics IIO(2): 353-377.

Key Scottish Environmental Statistics (KSES). 2006. Key Scottish Environmental Statistics 2006. Scottish Executive National Statistics. http://www.scotland.gov.uk/Resource/Doc/92I/0036584.pdf [24 January 2007]

Khan SR, Qureshi MS, Khan SR, Khwaja MA. 2003. The Costs and Benefits of Compliance with International Environmental Standards: Pakistan Case Study. Sustainable Development Policy Institute (SDPI). http://www.tradeknowledgenetwork.net/ pdf/tkn_pakistan_standards_sum.pdf [24 January 2007].

Senat, Le. I999. Les Conséquences des Normes Techniques pour les Collectivités Locales, rapport d'information du Senat. http:// lesrapports.ladocumentationfrancaise.fr/BRP/OI4000332/0000.pdf [24 January 2007] (in French).

Vogel D. I986. National Styles of Regulation. Cornell University Press.

WS Atkins plc. 2005. Mid-Term Review of the United Kingdom's Implementation of the Integrated Pollution Prevention and Control Regulation, draft final report. 